\title{
Figura DE BRONCE CON REPRESENTACión DE HÉRCULES PROCEDENTE DE Málaga
}

\section{Bronze figure representing Hercules from Málaga}

\section{ALEJANDRO PÉREZ-MALUMBRES LANDA ${ }^{1}$ @ , JUAN ANTONIO MARTÍN RUIZ²}

(1) Junta de Andalucía. Delegación Territorial de Cultura y Patrimonio Histórico, Málaga. alejandro.perezmalumbres@juntadeandalucia.es

(2) Universidad Internacional de Valencia. jamartinruiz@ hotmail.com

\section{RESUMEN:}

Damos a conocer una figura de bronce con la representación de Hércules hallada en las excavaciones realizadas en los números 57 a 61 de la calle Granada en Málaga, donde se pudo documentar una zona de carácter industrial relacionada con diversas actividades productivas. Restaurada por el Instituto Andaluz de Patrimonio Histórico, donde se realizaron análisis metalográficos, esta pieza puede fecharse en el s. I a.C., por lo que resulta ser uno de los escasos bronces con la imagen del héroe griego que pueden datarse de los localizados en los antiguos asentamientos coloniales repartidos por el Estrecho de Gibraltar. Al haberse descubierto en una antigua colonia fenicia, como es Malaca, se estudia también su vinculación con el dios fenicio Melqart, cuyo sincretismo con Hércules es bien conocido, así como la posible existencia de su culto en esta ciudad.

Palabras clave: bronce, Hércules, Melqart, fenicios, Málaga.

\section{Abstract:}

We present a bronze figure with the representation of Hercules found in the excavations made at numbers 57 to 61 of Granada Street in Malaga, where an area of industrial character related to several activities could be documented. Restored by the Andalusian Institute of Historical Heritage, where metallographic analyzes were carried out, this piece can be dated to the 1 st century BC, reason why it turns out to be one of the few bronzes with the image of the Greek hero that can be dated from those located in the old colonial settlements distributed by the Strait of Gibraltar. Having been discovered in an ancient Phoenician colony, as is Malacca, it is also studied its connection with the Phoenician god Melqart, whose syncretism with Hercules is well known, as well as the possible existence of his cult in this city.

Key words: bronze, Hercules, Melqart, phoenicians, Málaga . 
La estrecha relación que Hércules tuvo con las tierras situadas en el extremo occidente mediterráneo es sobradamente conocida, puesto que fue aquí donde el héroe heleno logró separar ambas orillas del Estrecho de Gibraltar creando así sus dos famosas columnas, Calpe y Abyla, que durante largo tiempo fueron consideradas el fin del mundo conocido, a la par que permitía de esta forma la comunicación entre las aguas del Atlántico y el Mediterráneo. Además, también lo vemos llevando a cabo dos de sus doce célebres trabajos ordenados por el rey Euristeo de Micenas, aunque dicho número puede variar puesto que en las puertas del santuario de Melqart en Cádiz solo se recopilaban una decena (Almagro-Gorbea y Torres Ortiz 2010: 195-198) y otros autores proponen que fueron hasta una veintena (Mederos Martín 2009: 198). En concreto, y desde el punto de vista canónico, se vinculan con su venida hasta el remoto occidente el décimo, que consistía en robarle los rebaños de bueyes a un gigante de tres cabezas llamado Gerión, y el undécimo en el que se le ordenaba hacer lo propio con las manzanas de oro del Jardín de la Hespérides (Gibbons 1975: 259-290; Humbert 1984: 120-128).

Esta circunstancia, junto con algunos aspectos de su figura como sucede con su resurrección, hace que no resulta extraño que con el paso de los siglos se fuese produciendo un proceso de sincretismo con el Melqart fenicio que, como no podía ser de otra forma, afectó a las colonias fenicias que antaño conformaron el Círculo del Estrecho. Ello ha propiciado que se hayan conservado esculturas, epígrafes y bronces en los que se le alude o representa, si bien en el caso de estos últimos por desgracia la mayor parte de los hallados en estos establecimientos de origen colonial carecen de un contexto arqueológico con el que poder vincularlos y, por extensión, tener la posibilidad de situarlos en un ámbito temporal adecuado, circunstancia que vuelve a repetirse si nos referimos a un buen número de ejemplares procedentes de enclaves de ascendencia indígena.

No cabe duda de que esta falta de contexto confiere un indudable interés a la pieza que presentamos en estas páginas, al haber sido descubierta en el transcurso de unas excavaciones arqueológicas llevadas a cabo en la calle Granada de la capital malagueña, y que ya fue dada a conocer aunque solo sumariamente tras una primera limpieza y consolidación por los profesionales de Quibla Restaura, antes de la restauración a que fue sometida en el Instituto Andaluz de Patrimonio Histórico (Pérez-Malumbres Landa 2012: 382). Por ello creemos oportuno realizar en estas páginas un estudio detallado de la misma, máxime cuando no solo ahora es posible apreciar sus características con mucha mayor claridad, sino que también disponemos de los resultados de los análisis metalográficos llevados a cabo en dicha institución y que por el momento resultan ser los únicos realizados a ejemplares metálicos de este tipo procedentes de enclaves coloniales.

Además, este hallazgo nos permite estudiar la presencia de esta figura mítica en el ámbito colonial fenicio del extremo occidente, así como su vinculación con el panteón religioso de estos navegantes orientales, en especial con el dios Melqart, haciendo hincapié en las figuras broncíneas de este mítico personaje que han sido documentadas hasta el momento en estos yacimientos meridionales, cuyo número es sumamente escaso como tendremos ocasión de comprobar más adelante y que se incrementa con la publicación de este ejemplar malacitano.

\section{EL CONTEXTO ARQUEOLÓGICO}

La figurilla fue descubierta el año 2008, en el transcurso de la segunda fase de la intervención arqueológica preventiva realizada siguiendo las indicaciones de la Delegación Provincial de la Consejería de Cultura de la Junta de Andalucía en la malagueña calle Granada, núms. 57 a 61 (fig. 1). Justamente por esta sinuosa calle transcurría el antiguo arroyo de El Calvario, conformando así el límite noroccidental de la zona ocupada por la primitiva colonia fenicia, cuyo cauce no fue cegado en su totalidad hasta la época califal y donde se ha sugerido que pudo haber existido un puerto natural (García Alfonso 2012: 353-354). La zona, hoy alejada de la costa pero que en la antigüedad se encontraba en las proximidades del mar, cuenta con una larga pervivencia en su ocupación que queda reflejada por la existencia de un área funeraria en la cercana calle Beatas de cronología ya tardía pues se fecha en el s. I a.C. (Martín Ruiz 2018: 53), así como por una zona comercial relacionada con el puerto desde sus orígenes.

Los trabajos arqueológicos emprendidos (fig. 2) han permitido documentar los restos de varias edificaciones de planta rectangular construidas con mampostería, cuyas estancias se articulan a ambos lados de una calle que contaba en torno a 1,5 m de ancho y que discurría en sentido aproximado $\mathrm{N}-\mathrm{S}$, de forma paralela a un arroyo cercano que hoy transcurre embovedado bajo la calle. 


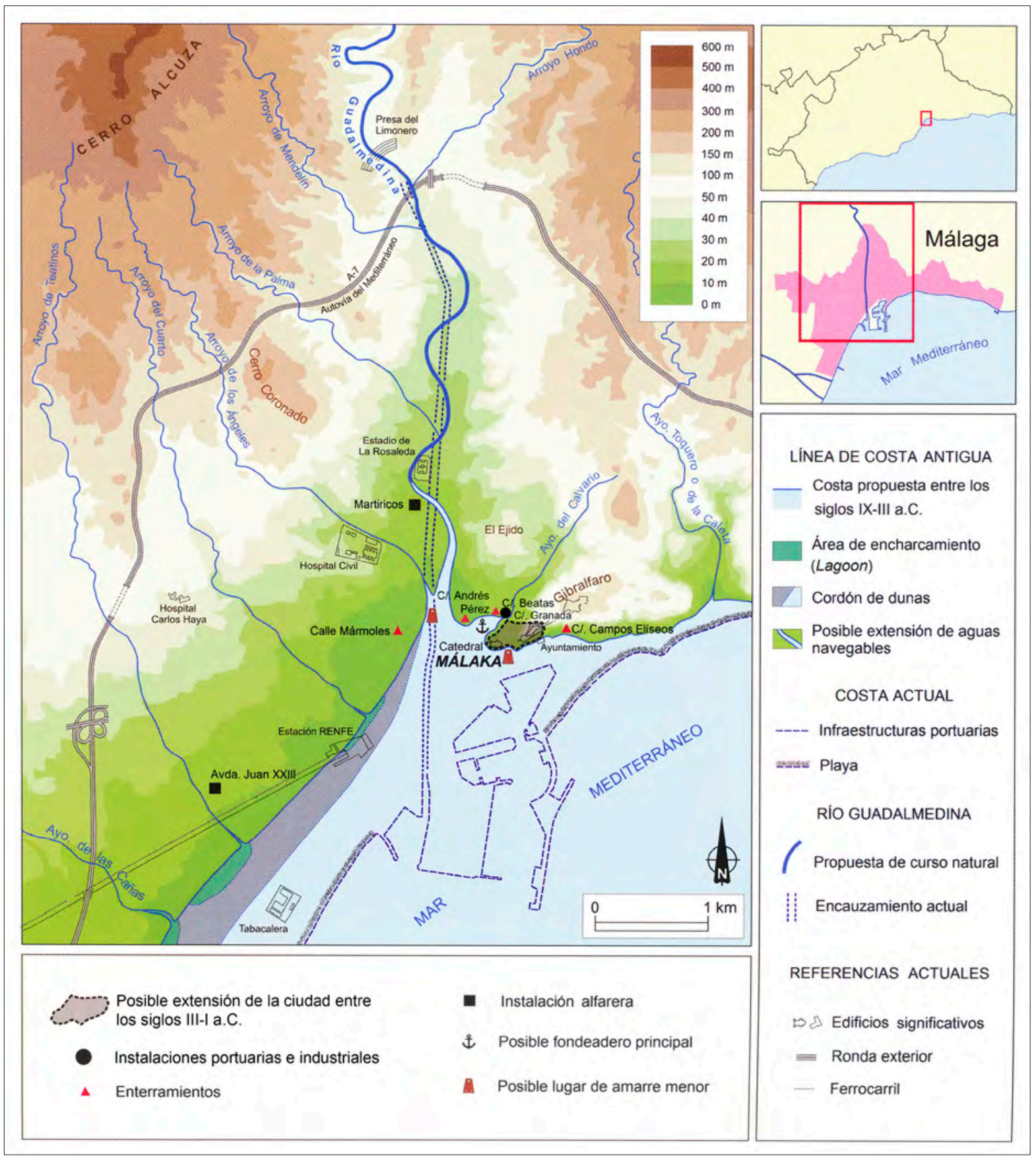

Fig. 1: Mapa de situación del solar en Málaga (Fuente: García Alfonso y Téllez Boigues).

Como podremos constatar, el contexto de su hallazgo ha sido datado en el s. I a.C., momento en el que sobre la primera fase constructiva del solar se produce una reordenación, acompañada de un recrecimiento de las cotas mediante rellenos que en diversos sectores del solar ha podido comprobarse que se acompañan de la instalación de un sistema de drenaje del terreno, mediante la colocación de ánforas completas o bien en grandes fragmentos en posición horizontal y, a veces, acopladas entre sí. Así mismo, al $\mathrm{S}$ de la zona del hallazgo se exhumó una cetaria 


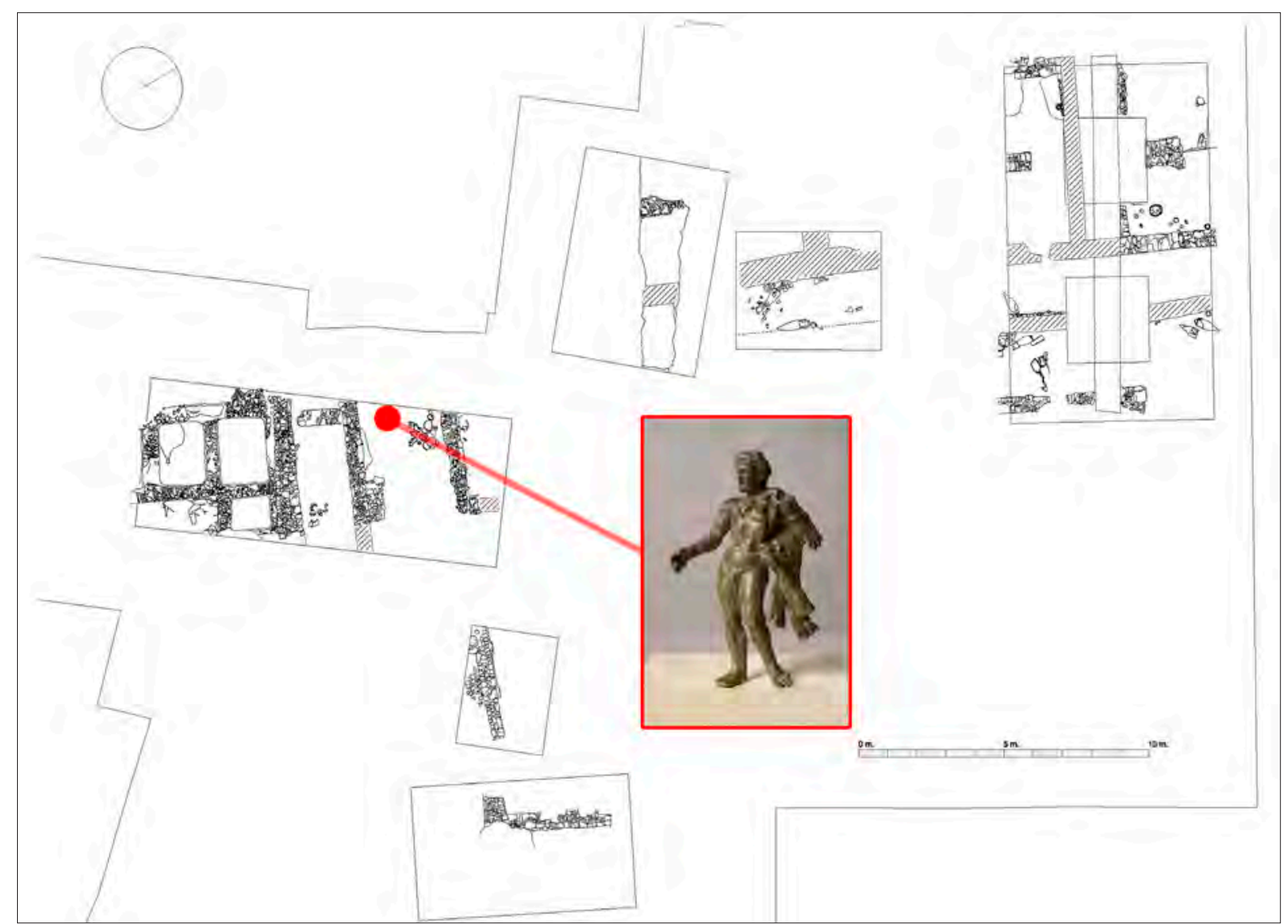

Fig. 2: Ubicación del hallazgo dentro de la excavación (Fuente: Pérez-Malumbres Landa y Téllez Boigues).

que resulta ser la más antigua conocida hasta el momento en la ciudad, integrada por cuatro piletas y a las que podemos añadir un espacio abierto con suelo de opus signinum que habría servido como zona de despiece (PérezMalumbres Landa 2012: 364-372).

Justo al $\mathrm{N}$ de este conjunto, en un espacio alterado en los niveles superiores por la rotura de diversos pozos modernos y contemporáneos, documentamos un complejo estructural formado por varias estancias rectangulares, superpuestas en parte a la fase constructiva inferior, constituido por los muros UEM 6282 (superpuesto al 6304 anterior) y UEM 6316, mientras que más al S el muro UEM 6276 del nivel inferior es amortizado y sustituido por un potente muro de nueva planta, la UEM 6250 , que conforma un espacio más estrecho que la distribución anterior (2,80 respecto a 3,80 m), cerrando dicho espacio a la citada calle por el O la UEM 6194, presente ya en la fase anterior. Como en otros muros de esta fase en su construcción se emplearon mampuestos muy bien ajustados de variado tamaño y naturaleza (caliza, esquistos...), destacando por su tamaño un sillarejo de travertino en el frente $\mathrm{N}$ de la UEM 6250. Del mismo muro, al igual que en otros del mismo nivel situados más al $\mathrm{N}$ y en el corte 3 , recuperamos diversos fragmentos de ánforas insertos como mampuestos en su estructura, incluyendo bases y bordes de ánforas Mañá C2, fragmentos de campaniense A tardía y murex, así como un fragmento de un elemento arquitectónico cerámico que formaba parte de un capitel jónico, el cual presenta decoración de un kymation de cinco ovas enteras enmarcadas por moldura y separadas por flechas, conservándose el plano inferior con astrágalo liso, mientras que en el plano superior faltan las volutas y el ábaco.

El nivel de uso asociado queda establecido en torno a las cotas 7,31 y 7,34 m snm, siendo en el relleno preparatorio al mismo donde cabe destacar la aparición en la UE 6281 de una estatuilla de bronce representando a Hércules, así como un fragmento de cuenco cerámico con cabeza femenina en relieve en la unidad coetánea UE 6268. Entre los materiales recuperados en esta fase cabe 
Fig 3: Vistas de la figura de Hércules (Fuente: Bronce romano con representación de Hércules del Museo de Málaga. Archivo IAPH. Autor: E. Fernández Ruiz).

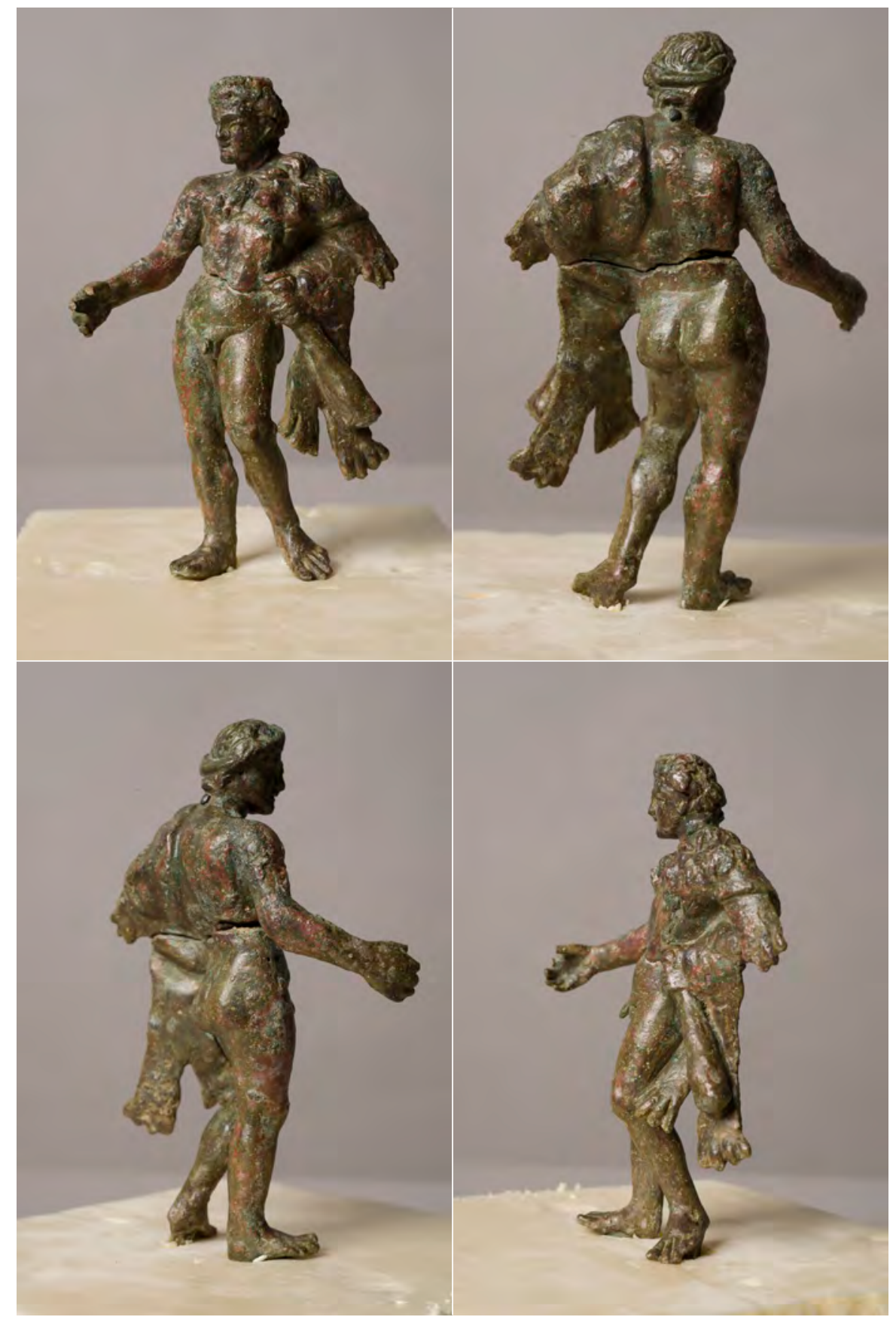

comentar la presencia de piezas de tradición fenicia junto a otras de clara raigambre itálica. Entre ellos podemos citar las ánforas grecoitálicas, Dressel IC y 7/11, Haltern 70 y Lomba do Canho 67, si bien las más numerosas son sin duda las Mañá C2b, a veces con defectos de cocción, además de vasos campanienses de las clases A tardía y B. Otro tanto sucede con las cerámicas de paredes finas, varias de ellas pertenecientes a la forma Mayet VIII, que en algunos casos pueden incluso tratarse de imitaciones locales, sin olvidar las jarras y los morteros con repié, a los que cabría sumar las cerámicas de cocina como las cazuelas con borde bífido con desgrasante muy fino de mica, y algunos fragmentos de vasos de barniz rojo pompeyano (Pérez-Malumbres Landa 2012: 378-382). 
Así pues, en consideración a los materiales asociados, parece factible situar temporalmente el establecimiento de este nivel de uso en el s. I a.C.

A tenor de los hallazgos realizados podemos señalar que las estructuras exhumadas en este punto de la ciudad muestran un claro carácter productivo relacionado con las industrias salazonera y alfarera (Pérez-Malumbres Landa 2012: 388), las cuales se encontrarían aledañas al puerto (García Alfonso 2017: 353-354), así como comercial, como hemos visto atestiguado por los abundantes materiales de importación. Con posterioridad a dicha ocupación se documenta la continuidad de la industria alfarera junto a otras actividades productivas, tales como varias pistrina (Pérez-Malumbres Landa 2018: 91), en tanto algunos indicios parecen avalar que aquí se trabajaron materiales como el vidrio o el hueso.

\section{EL BRONCE}

Se trata de una figura maciza de bronce, conservada actualmente en el Museo Arqueológico de Málaga con el número de inventario A/DJ14417/6281.020. Con una altura de $14 \mathrm{~cm}$, un ancho de $8 \mathrm{~cm}$ y un grosor de $3 \mathrm{~cm}$, se aprecia un vástago en el pie derecho que debió servir para insertarlo en una peana y sustentarlo verticalmente. Representa a Hércules joven, desnudo e imberbe, tocado con una corona de laurel o una cinta en la cabeza (fig. 3), de muy cuidada factura pues los detalles de la nariz, ojos, cabello, etc. muestran un buen acabado, si bien hay una cierta desproporción que lo aleja de los cánones clásicos. Especialmente, los brazos y piernas aparecen representados muy robustos, quizás como un modo de celebrar su fuerza física. Mientras que su pierna derecha se muestra recta, la izquierda se flexiona, en tanto su brazo derecho se adelanta sin que quepa descartar que portase algún objeto puesto que presenta una pequeña fractura en su mano, de modo que le falta el pulgar y las dos primeras falanges del dedo índice. Este objeto podría muy bien ser una manzana, lo cual es plenamente factible puesto que este fruto hace acto de presencia en estas figurillas a partir de la época helenística, como sucede cronológicamente con este ejemplar (Palagia 1990: 57). También hay representaciones en las que sostiene un vaso para beber, un skyphos o kantharos, tipo conocido como Hercules Bibax o Diouxumenos, si bien en este caso la mano suele estar en posición horizontal. Sin embargo, dado que es posible encontrar paralelismos con otra figura hallada en Durostorum que representa a Hércules joven con la mano en actitud de saludo (Georgiev 1995: 261), o con aquella otra también en actitud de reposo que procede de Iasos (Malgieri 2008: 24) y que vemos igualmente en el bronce descubierto en Sagunto (Oria Segura 1998: 219-220), hace que no podamos descartar que pudiera estar tendiendo su mano abierta en actitud de saludo, máxime cuando ésta se encuentra situada verticalmente. Su brazo izquierdo se dobla en su codo para apoyar su mano en la cintura, sosteniendo una clava que no llega a apoyar en el suelo y la piel del león de Nemea que cubre el hombro y se anuda alrededor del cuello, donde se pueden apreciar las garras Así mismo, cabe señalar una fisura que lo atraviesa horizontalmente un poco más arriba de la cintura, que puede ser debida a un defecto en la fundición.

Como se ha indicado, estos bronces muestran una gran variedad formal en su ejecución (Oria Segura 1998: 80 ), lo que explica que no encontremos un paralelo fielmente exacto para esta figura. Genéricamente puede incluirse dentro de la Variante B del tipo II de la clasificación establecida por Fernández Uriel (2007: 288), en la que se incluyen los bronces de Hércules con clava y leonté, bien sobre el hombro o sobre uno de los brazos.

La realización por el Instituto Andaluz de Patrimonio Histórico de análisis arqueometalúrgicos, junto con algunas radiografías, aportan interesantes datos sobre esta pieza, teniendo en consideración que en todo caso se recurrió al uso de técnicas no destructivas a fin de asegurar su correcta preservación. En consecuencia, su composición fue examinada mediante Fluorescencia de Rayos X siendo además tres las muestras estudiadas en las que se empleó la técnica de isótopos de plomo mediante espectrometría de masas con fuente de plasma acoplada inductivamente, tomando muestras de peso en cantidad menor a un gramo, una de la cabeza, otra de la nalga derecha y una última del tobillo, las cuales evidenciaron que se trata de un bronce ternario con alto contenido de plomo e impurezas de hierro y estroncio.

Así, la primera muestra indicaba la existencia de un $46,77 \%$ de cobre, un $39,98 \%$ de plomo y un $10,19 \%$ de estaño, habiéndose detectado impurezas de hierro $(2,74 \%)$ y estroncio $(0,31 \%)$. Por su parte, en la segunda se detectó una composición formada por un $48,36 \%$ de cobre, $41,46 \%$ de plomo, $8,33 \%$ de estaño, $1,66 \%$ de hierro y $0,2 \%$ de estroncio. Finalmente, la tercera de las muestras evidenció que estaba constituida por un $30,84 \%$ de cobre, un $55,01 \%$ de plomo y un 7,65\% de estaño, junto con un $6,51 \%$ de hierro, todo lo cual queda reflejado en 


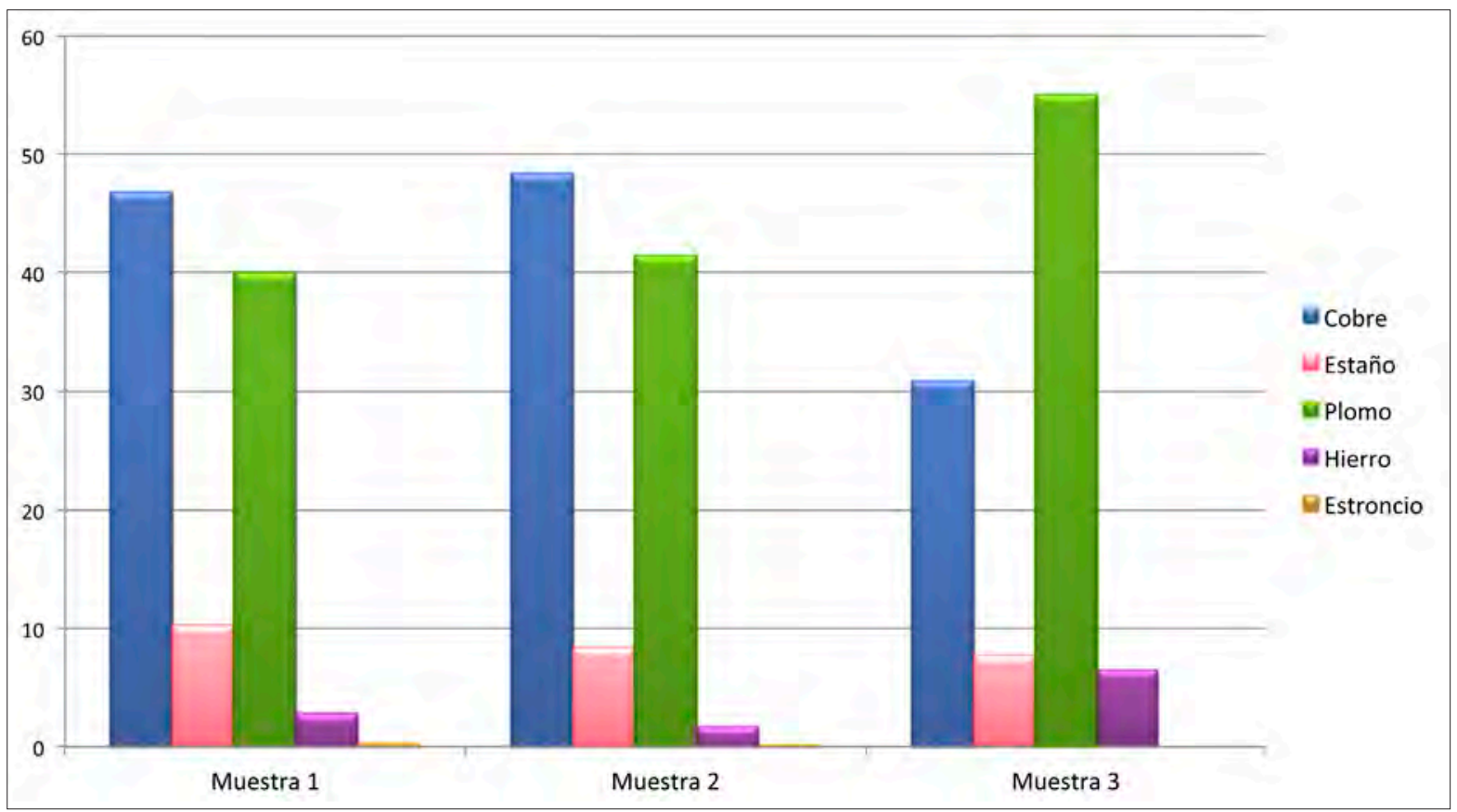

Fig 4: Composición de las distintas muestras analizadas (Fuente: elaboración propia a partir de Archivo IAPH).

el siguiente gráfico (fig. 4). Estos datos vienen a poner de manifiesto que la figura fue elaborada de tal forma que el molde estaba dirigido con la cabeza hacia arriba, lo que explica que el porcentaje de plomo sea mayor en los pies que en la parte superior (Hunt Ortiz 2014: 9-19).

Además, cabe indicar que esta elevada concentración de plomo resulta muy apropiada si se desea conseguir una colada lo bastante fluida como para permitir una mejor calidad a la hora de ejecutar los detalles de la obra, lo que por otro lado podría hablarnos de la utilización de un molde de arcilla a la cera perdida para su fabricación. De todo lo dicho puede deducirse que el artesano que elaboró este objeto dominaba las labores metalúrgicas a la perfección, si bien no estamos todavía en condiciones de estipular el lugar en el que fue fabricado.

\section{HÉRCULES COMO MELQART: SU PRESENCIA EN LAS COLONIAS FENICIAS DEL CÍRCULO DEL ESTRECHO}

Como es sabido, durante la Antigüedad se produjo un proceso de sincretismo en virtud del cual la figura de Heracles/Hércules, nacido en la ciudad de Tebas según Hesíodo (Teog. 530), fue asimilada a la del dios fenicio
Melqart, el más importante de la ciudad de Tiro (Jensen 2002: 102-108) y al que se le atribuía la invención de la escritura y la industria de la púrpura, siendo así mismo garante del comercio y la navegación con un marcado carácter guerrero (Poveda Navarro 1999: 30). En el extremo occidente su culto está constatado en el célebre templo gaditano, donde incluso se situaba su sepultura tras haber sido muerto en Libia por Tifón, consistente en un monumento con varios pisos que remataba en una pirámide coronada por una escultura del dios fenicio en bronce dorado que era visible desde lejos y que fue destruida en el s. XII d.C., la cual ha sido datada de forma aproximada en época helenística con relación a la presencia bárcida aunque con bastante probabilidad sobre alguna estructura de época anterior (Almagro-Gorbea y Torres Ortiz 2010: 67-86; Almagro-Gorbea 2014: 169-182),

Como no puede ser de otra forma, su imagen está difundida en estos asentamientos de origen oriental como vemos, por ejemplo, en los escarabeos de los ss. V-IV a.C. procedentes de la isla de Ibiza (Vives i Escudero 1917: 70-71; Fernández y Padró 1982: 149-154; Velázquez et al. 2015: 111-113). Además, en la investigación sobre el tema se suele aceptar que una serie de bronces fenicios datados entre los ss. VIII-VII a.C., algunos de ellos hallados en Cádiz o Huelva y conocidos con el 
nombre de smiting gods, serían representaciones de Melqart siguiendo un modelo estrictamente oriental (Corzo Sánchez 2005: 38; Zambrano Valdivia 2010: 228), aunque otros investigadores han puesto de manifiesto la dificultad que existe a la hora de atribuirlos a una divinidad en concreto a pesar del elevado número de candidatos que se han sugerido (Jiménez Ávila 2002: 282-285). En este sentido se ha planteado un posible préstamo iconográfico ya que estas figuras en origen eran imágenes de Baal y Reshef, e incluso de cierto sincretismo con esta última deidad como demostraría una placa de bronce de los ss. V-IV a.C. descubierta en la cueva ibicenca de Es Cuiram, en la que ambos aparecen mencionados (Poveda Navarro 1999: 33).

Hasta el momento las imágenes más antiguas conocidas de esta deidad se remontan al s. VIII a.C. como vemos en la estela de Barhadad (Bonnet 1992: 186), y cuyo culto fue renovado e institucionalizado por Hiram I de Tiro, ciudad de la que era el dios principal, celebrándose su egersis entre febrero y marzo de cada año (Martín Ruiz 2008: 13), la cual aparece representada en un vaso de piedra del s. IV a.C. procedente de Sidón, siendo interesante recodar la existencia en Cartago de un $\mathrm{mqm}$ ' $\mathrm{lm}$

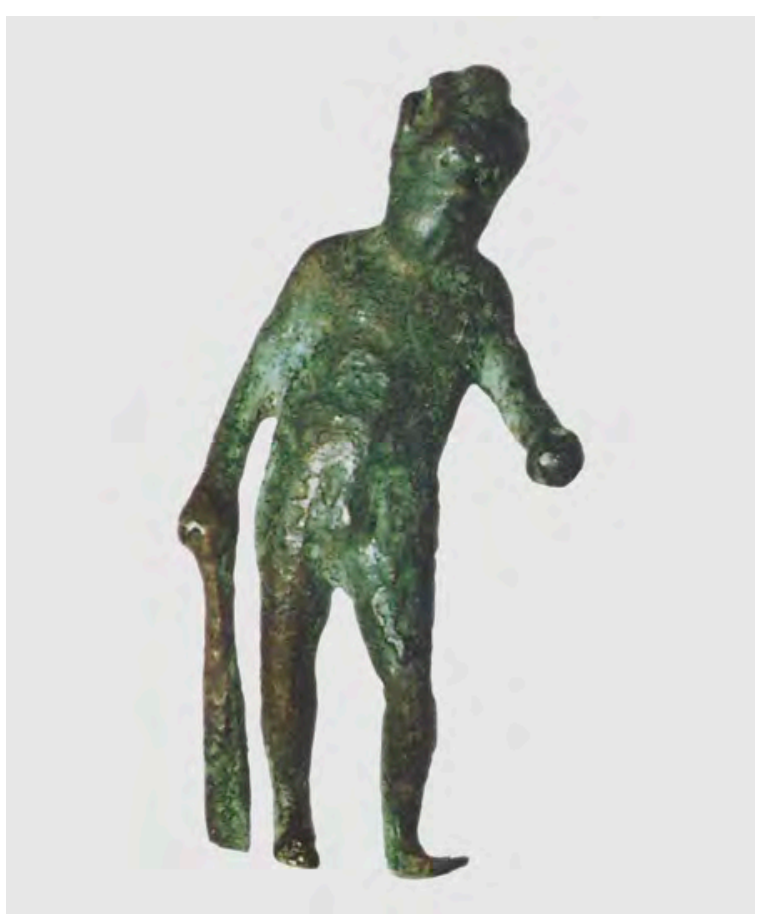

Fig 5: Bronce con representación de Hércules de Ceuta (Fuente: Rodríguez Oliva). "resucitador de la divinidad" (Bonnet 1992: 286). En Cádiz se llevaba a cabo esta celebración religiosa con una duración de tres días, en los que se entonaban cantos fúnebres y en cuyo final se procedía a quemar una efigie del dios sobre un hipocampo hecha de madera (AlmagroGorbea y Torres Ortiz 2010: 101).

Sin embargo, las investigaciones realizadas en los últimos años han puesto de manifiesto cómo desde el s. VI, y sobre todo a lo largo del V a.C., su iconografía oriental fue siendo sustituida por otra de tipo griego (Oria Segura 1998: 27-28; 2002: 227; Poveda Navarro 1999: 35), proceso que según algunos autores habría tenido lugar en la isla de Chipre (Bonnet 1992: 287). Quizás unos párrafos de Herodoto (II, 44) aludan a este hecho al indicar que algunos griegos lo adoraban como dios y otros como héroe. No obstante, ello no es obstáculo para que todavía en su segunda mitad encontremos alguna figurilla que, aunque sigue el modelo fenicio anterior, muestra cierta evolución por cuanto aparece desnudo sin que porte ya el típico tocado y sí una piel de león sobre sus hombros (Fernández Gómez 1985: 370-375). De todas formas esculturas de la calidad del denominado Efebo de Mozia, considerada una imagen de Hércules-Melqart del s. V a.C., ponen claramente de manifiesto la plena asunción por parte fenicia de estos modelos helenos (Moreno 1995: 547-550), modelos que a partir de la época helenística serán los imperantes como pone claramente de manifiesto un bronce de Biblos datado en el s. I d. C. conservado en el British Museum (Palagia 1990: 57-58). Su presencia fue tan notable que algunas ciudades lo eligieron como emblema de los anversos de sus acuñaciones monetarias, según cabe advertir en Gadir (Alfaro Asins 1988: 35-36), Carteia (Chaves Tristán 1979: 21-23) o Sexs (Alfaro Asins 1986: 76 y 79).

Son varias las figuritas de bronce en las que se representa a este héroe que han sido halladas en las antiguas colonias fenicias repartidas por el Círculo del Estrecho. Una de ellas maciza con 7,2 cm de altura, conservada en una colección particular (fig. 5), procede de Ceuta donde se halló en 1920 sin contexto y, por consiguiente, de cronología incierta, aun cuando parece que fue extraída sin control de alguna excavación emprendida a comienzos del pasado siglo (Hita Ruiz y Villada Paredes 2017: 1402). Desnudo, barbado y en pie con la clava en la mano derecha y la leonté sobre la cabeza, no se descarta que portara una manzana en su mano derecha (Rebuffat 1971: 183-184; Rodríguez Oliva 1988: 907-908). Otro tanto acontece con otra pieza procedente de Carteia que se 


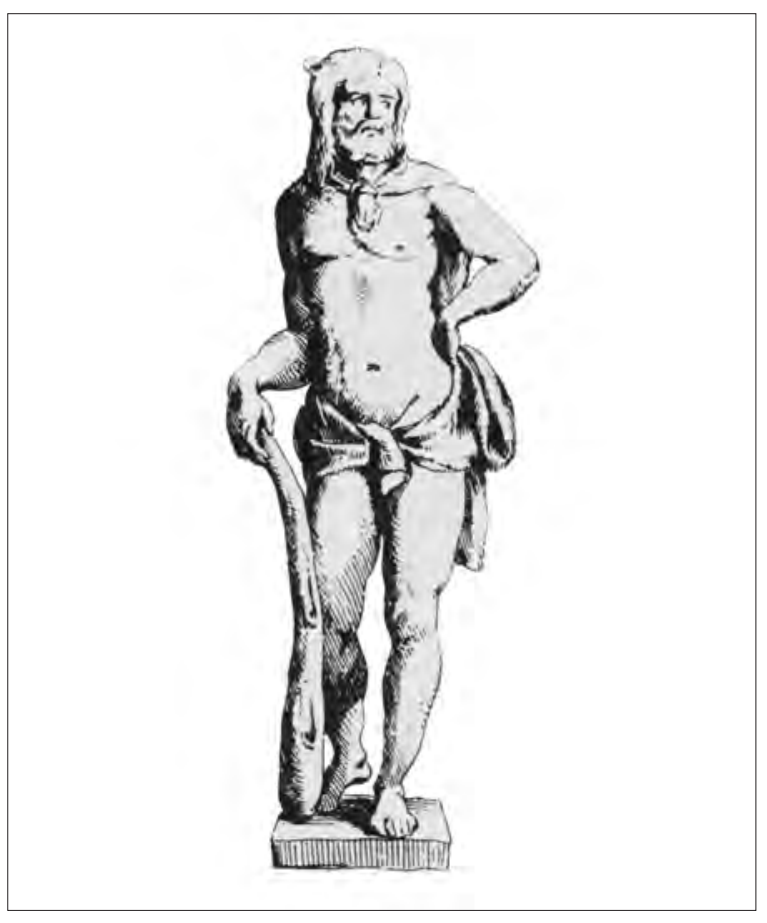

Fig 6: Figura de Hércules hallada en Cádiz en el s. XVIII (Fuente: Rodríguez Oliva).

custodia en el Museo Arqueológico Nacional cuya altura alcanza los $8 \mathrm{~cm}$ en la que se representó de pie, desnudo con barba y tocado con una corona de laurel, la mano derecha extendida con una manzana y clava y leonté en la mano izquierda (Oria Segura 1993: 177; 1996: 212), enclave donde incluso se han documentado tégulas con estampillas en las que se lee su nombre (Rodríguez Oliva 1988: 910).

Algo similar sucede en el caso gaditano donde se han descubierto dos bronces, si bien de uno de ellos, en la actualidad perdido (fig. 6), se duda incluso de su fecha de aparición, puesto que si algunas fuentes nos indican que fue arrojado por las mareas en la playa de Santi Petri en 1631, otras lo sitúan en el año 1755 con ocasión del famoso terremoto de Lisboa (García y Bellido 1963: 86; Rodríguez Oliva 1988: 912-913). Sea como fuere, esta pieza formó parte de la colección que el gaditano Guillermo Tyrry, Marqués de la Cañada, tenía en El Puerto de Santa María, siendo conocida solamente por un dibujo que él mismo remitió al anticuario francés Conde de Caylus (Rodríguez Oliva 1990: 94-95) en el que se aprecian ciertas libertades por parte de su autor, apareciendo citada en una relación publicada en 1795 por Pedro Alonso

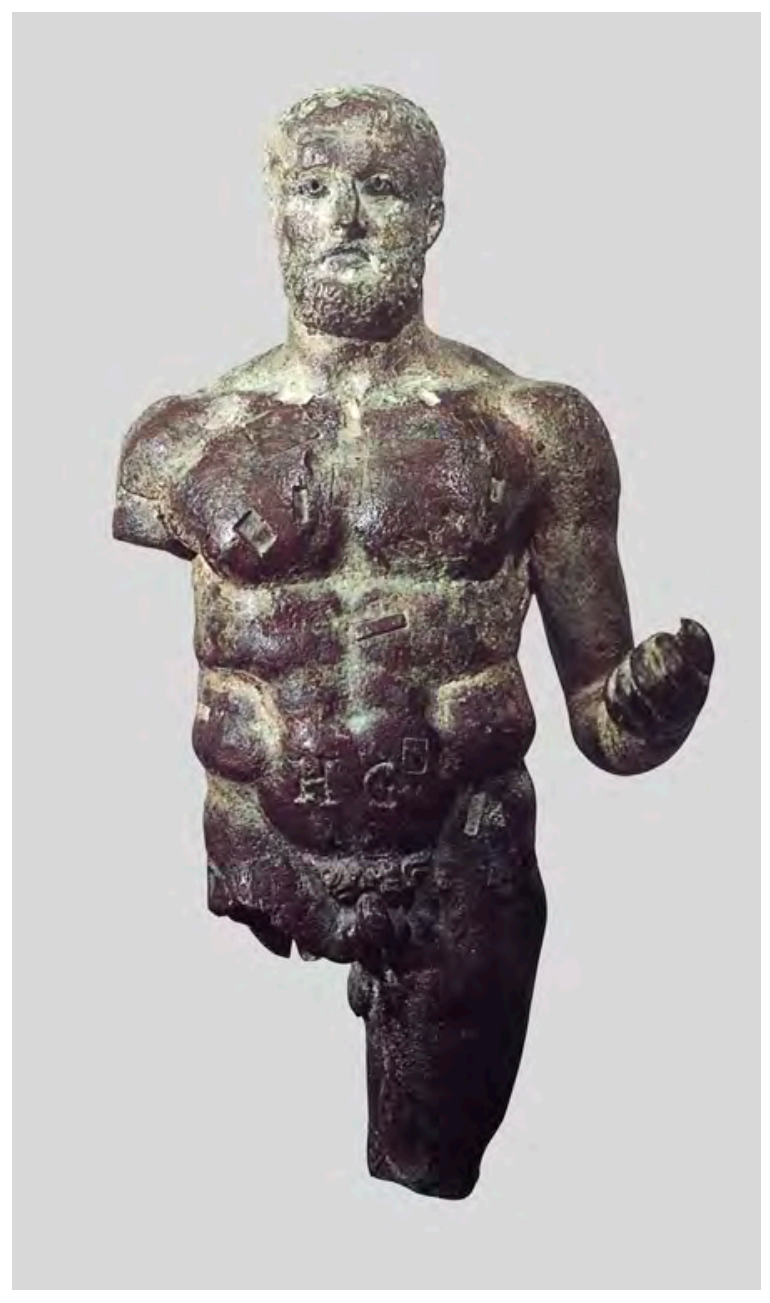

Fig 7: Imagen de Hércules de Cádiz (Fuente: Martín Ruiz).

O'Crouley (Sánchez Cantón 1943: 220). En ella se advierte que estaba como todas las conocidas hasta ahora en pie, barbado y desnudo con la leonté sobre la cabeza y anudada al cuello y la cadera (Oria Segura 1996: 211).

La segunda pieza está fundida en hueco con ojos incrustados y fue descubierta en 1984 en la zona de Santi Petri conservándose hoy en día en el Museo Arqueológico Provincial de Cádiz, a la que le faltan parte de las piernas, aun cuando la izquierda se conserva hasta casi la rodilla, y el brazo derecho a partir del hombro. También en pie, desnudo y barbado con la mano extendida en la que se ha sugerido habría portado una manzana; en su torso musculado se grabaron las letras $\mathrm{H}$ (erculis) $\mathrm{G}$ (aditani) (fig. 7) por lo que se ha sugerido pudo pertenecer al propio templo y que sería una copia de la escultura 
de Hércules realizada por Mirón en la isla de Samos, el cual se ha datado en época alto imperial (Corzo Sánchez 2004: 41-45; Oria Segura 1996: 201-211; 2002: 226). También está presente en otro importante centro norteafricano como es Lixus que se expone en el Museo de Rabat (fig. 8), alcanzando los $35 \mathrm{~cm}$ de altura fundido en hueco de gran calidad artística y técnica, si bien en esta ocasión responde a un modelo diferente por cuanto se le representa en plena lucha contra Anteo a quien desde atrás sujeta por ambos brazos, mostrándolos a ambos desnudos y barbados con aspecto musculoso (Blázquez Martínez 2008: 183-186), ya que no es seguro que otro fragmento corresponda a la leonté de otra pieza (Rebuffat 1971: 186) por lo que preferimos no incluirlo.

En el caso concreto de Malaca las excavaciones arqueológicas desarrolladas a lo largo de las últimas décadas han permitido constatar la existencia de restos de un templo datado hacia finales del s. VII e inicios del VI a.C. (Escalante Aguilar et al. 2012: 89-94), pero sin que hasta el momento tengamos evidencias seguras de que tuviera

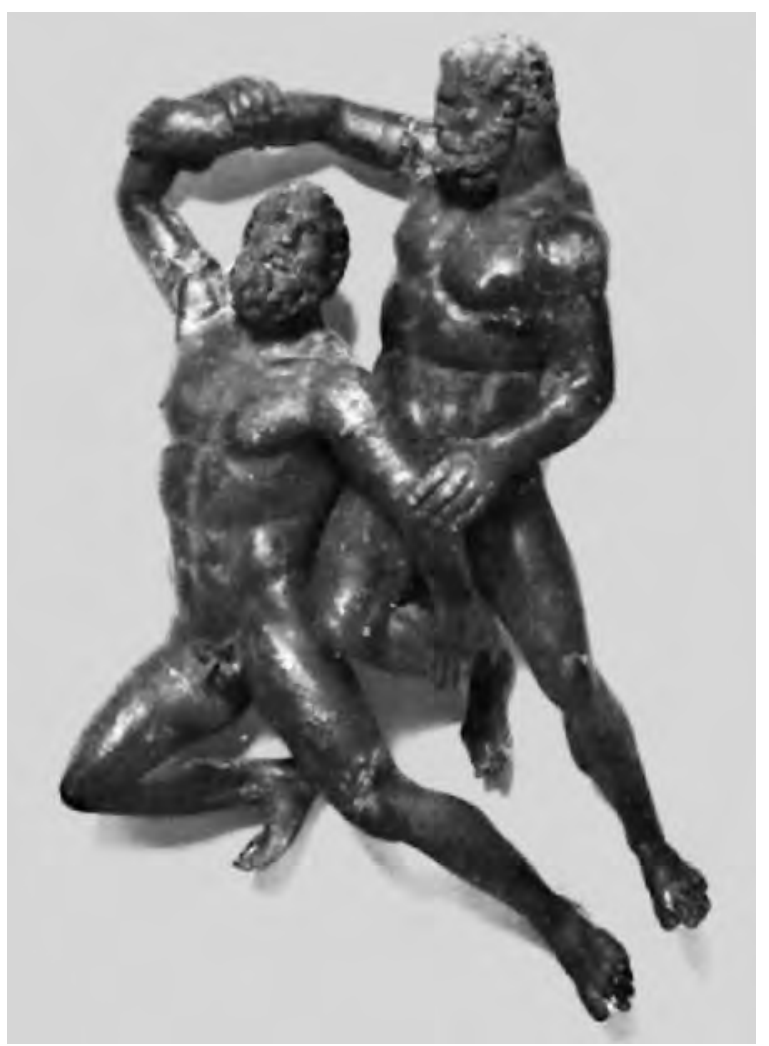

Fig 8: Grupo broncíneo de Hércules y Anteo procedente de Lixus (Fuente: Blázquez Martínez). lugar un culto a Melqart, máxime cuando se han hallado altares con forma de piel de toro que se viene aceptando simbolizarían a otro dios como es Baal (Escacena Carrasco e Izquierdo de Montes 2000: 15-25). Y tampoco tenemos información acerca de cuáles pudieron ser las advocaciones a las que estuvo dedicado un templo tetrástilo que vemos representado en algunas de las monedas acuñadas en la propia ciudad (Mora Serrano 1981: 38-39).

Sin embargo, no debemos olvidar que algunos autores han sugerido que la efigie que vemos representada en los anversos de las monedas acuñadas en su Período I sería una imagen de esta deidad (Moreno Pulido 2014-2015: 159-161), e incluso que sería uno de los dioses acuñados en las emisiones posteriores (Blázquez Martínez 2006: 94 95). A ello podemos sumar ya en época alto imperial romana la presencia de varios fragmentos de mármol blanco de las canteras de la sierra de Mijas que podrían pertenecer a una escultura de Hércules, tal vez hallados en los derribos de la alcazaba efectuados a comienzos de la pasada centuria, la cual pudo formar parte de una fuente y que se ha datado hacia mediados del s. II d.C. (Baena del Alcázar 1984: 166-167; Oria Segura 1996: 200-201). Así mismo, el carácter salutífero de esta figura heroica puede apreciarse en la inscripción ubicada en una torre situada junto a la puerta llamada del "Vizcocho" de la Alcazaba y realizada en un pedestal de mármol blanco, el cual debió sustentar una estatua de plata que un tal Caius Veilius Domitius mandó erigir a Marte como señal de agradecimiento a Hércules Augusto por haberse curado de una herida que le habían infringido (García de la Leña-Medina Conde 1790, fol. 17; Sánchez de la Torre 2016: 87).

Ello nos lleva a plantearnos cómo debemos interpretar la aparición de esta figura broncínea intentando así ampliar la escasa información que tenemos sobre la relación de Hércules-Melqart con esta urbe. Lo parcial de una excavación preventiva no ha permitido determinar con claridad a qué estaban destinadas las distintas dependencias excavadas en la calle Granada, aun cuando en una primera instancia podríamos considerar su posible uso como tiendas. Sin embargo, la cercanía de unas instalaciones tan insalubres como son las piletas de salazón y posiblemente también hornos cerámicos, nos hace dudar de esta posibilidad por lo que parece más aconsejable valorarlas como estancias vinculadas con esta cetaria, tal vez unos almacenes e incluso sin descartar tampoco que alguna pudiera ser una dependencia para uso del personal. Si tenemos en cuenta que a estos bronces se les viene asignando una finalidad cultual (Oria Segura 1998: 79-80), 
cabe preguntarnos si este Hércules-Melqart podría haber pertenecido a las personas que trabajaron en estas instalaciones industriales, enmarcándolo en un culto privado de forma similar a lo que vemos en la mina de Mazarrón que estuvo en actividad entre los ss. I a.C. y II d.C., y donde en 1840 se descubrió una figurita broncínea de Hércules (Oria Segura 1998: 216). También podemos traer a colación el ejemplar de Carteia que ha sido puesto en relación con cultos privados (Oria Segura 1996: 212), así como otro hallado en Itálica sin un contex to conocido del que, no obstante, no se descarta que incluso pudiera haber formado parte de un larario al igual que se documenta en Pompeya (Oria Segura y Escobar Pérez 1994: 447 y 458). Este hecho los diferenciaría de los dos hallados en Cádiz que se vincularían con ofrendas marinas hechas en honor de la divinidad, y que son bien conocidas en la ciudad en relación con lugares de culto (Corzo Sánchez 1999: 30-37), mientras que desconocemos por completo el contexto en el que se hallaron los de Ceuta, Carteia y Lixus.

Además, aun siendo notorio su sincretismo con Melqart como hemos expuesto, tampoco debemos olvidar que nos hallamos en una fecha en la que las creencias romanas ya eran bien conocidas en la ciudad. En este sentido Hércules era para los romanos un eficaz garante del comercio, existiendo en Roma una advocación de Hércules en tal sentido, el conocido como Hércules ponderum o guardián de los pesos (Aubet Semmler 1987: 242; Pérez Zurita 2011: 118 y 141; Rodríguez Martorell y Ruiz de Arbulo 2016: 174-175).

La falta de contexto que muestran la totalidad de estas figuritas broncíneas, circunstancia que como es lógico dificulta asignarles una datación, otorga mayor interés al ejemplar que ahora presentamos ya que puede fecharse con seguridad en el s. I a.C. En este sentido el ejemplar malacitano que ahora estudiamos resultaría ser el más antiguo documentado hasta el momento, puesto que los dos gaditanos se datan en época alto imperial sin que se haya ofrecido una datación para las restantes.

\section{CONCLUSIONES}

Esta figura de bronce ternario con un alto contenido de plomo hallada en Malaca constituye una de las pocas imágenes broncíneas de Hércules procedente de un yacimiento de origen fenicio que puede asociarse a un contexto arqueológico definido. Además, su hallazgo viene a incrementar el escaso volumen de bronces de este tipo que han sido documentados en el área del Círculo del Estrecho, puesto que resulta ser el sexto ejemplar conocido, la mayoría de ellos en su vertiente septentrional. Aunque la información de carácter cronológico que tenemos sobre este tipo de bronces en esta zona es sumamente escasa, habida cuenta la falta de contexto de la práctica totalidad, esta pieza malacitana sería la más antigua de todas ellas por cuanto se dataría en el s. I a.C.

La pieza muestra cierta calidad artística y técnica en su fabricación, si bien no sucede lo mismo en lo referente a su composición metalográfica dado su elevado contenido en plomo, tendente a facilitar el proceso de fundición al mismo tiempo que se abarataba el producto final y facilitaba una mejor realización de los detalles artísticos. Creemos que lo más probable es que quepa relacionarla con algún culto privado, quizás incluso relacionado con el personal de estas instalaciones productivas, ya que cabe descartar por completo que se trate de una zona donde se llevó a cabo alguna actividad cultual de carácter público o funerario.

Si nos detenemos en examinar estos bronces hallados en las antiguas colonias fenicias del extremo occidente en su conjunto podemos advertir un detalle de interés, y es que esta figura malacitana resulta ser la única por el momento que no se muestra barbado, o lo que es lo mismo, que presenta un aspecto juvenil. Además, todos ellos se muestran de pie, ninguno sedente, los de Ceuta y el perdido de Cádiz con la leonté cubriendo la cabeza. Ninguna de estas figuras ha sido hallada en áreas de enterramiento por lo que no pueden vincularse con el mundo funerario, sino que las encontramos en asentamientos o en lugares de culto íntimamente vinculados con éstos. Tal vez los ejemplares gaditanos recuperados en ambos casos en el mar pudieran haber formado parte de prácticas rituales continuidad de otras constatadas para fechas más antiguas.

Dada su aparición en una ciudad fundada por los navegantes fenicios, no parece que exista problema alguno para relacionarlo con Melqart, cuyo sincretismo por otra parte está bien constatado en el mundo antiguo. Así mismo, conociendo la veneración que los romanos sintieron por Hércules no debe extrañarnos que su culto estuviera presente en Malaca durante la etapa romana alto imperial $\mathrm{y}$, como vemos ahora, también fue conocido en la última centuria antes del cambio de era. Aun cuando no es seguro, no resulta descartable que al menos ya desde finales del s. III a.C., fecha de la primera emisión monetaria de la ciudad, Melqart fuese uno de sus dioses titulares. 
En definitiva, podemos concluir diciendo que se trata de una pieza que viene a ampliar el reducido corpus de estas representaciones hercúleas en bronce conocidas en esta zona, siendo por el momento la única que aporta datos seguros sobre su contexto, cronología y composición metalográfica, lo que le confiere un indudable interés.

\section{BIBLIOGRAFÍA}

ALFARO ASINS, C. (1986): Observaciones sobre las monedas de Sexs en el MAN, Almuñécar. Arqueología e Historia, III (F. Molina Fajardo, ed.), Granada, 75-104.

ALFARO ASINS, C. (1988): Las monedas de Gadir/Gades, Madrid.

ALMAGRO-GORBEA, M. (2014): La tumba de Melqart' del Herákleion de Gadir, Madrider Mitteilungen 54, 159-202.

ALMAGRO-GORBEA, M.; TORRES ORTIZ, M. (2010): La escultura fenicia en Hispania, Madrid.

AUBET SEMMLER, M. E. (1987): Tiro y las colonias fenicias de occidente, Barcelona.

BAENA DEL ALCÁZAR, L. (1984): Catálogo de las esculturas romanas del Museo de Málaga, Málaga.

BLÁZQUEZ MARTÍNEZ, J. M. (2006): La religiosidad en el mundo fenicio del sur de Hispania, Mainake 28, 79-104.

BLÁZQUEZ MARTíNEZ, J. M. (2008): Mitos griegos en Lixus (Mauritania Tingitania). Los bronces de Hércules en lucha con Anteo, y de Teseo con el Minotauro, Anuario de Estudios Atlánticos 54, II, 169-194.

BONNET, C. (1992): Melqart, Dictionnaire de la Civilisation Phénicienne et punique (E. Lipinski, ed.), Bruxelles, 285-287.

CORZO SÁNCHEZ, R. (1999): Venus marina gaditana, Sevilla.

CORZO SÁNCHEZ, R. (2004): Sobre la imagen del Hércules Gaditano, Romula 3, 7-62.

CHAVES TRISTÁN, F. (1979): Las monedas hispano-romanas de Carteia, Madrid.

ESCACENA CARRASCO, J. L.; IZQUIERDO DE MONTES, I. (2000): Altares para Baal, Arys: Antigüedad, religiones y sociedades 3, 11-40.

ESCALANTE AGUILAR, M. M. (2012): El santuario fenicio de Malaka, Diez años de arqueología fenicia en la provincia de Málaga (2001-2010) (E. García Alfonso, ed.), Sevilla, 87-103.

FERNÁNDEZ, J. H.; PADRÓ, J. (1982): Escarabeos del Museo Arqueológico de Ibiza, Madrid.

FERNÁNDEZ GÓMEZ, F. (1985): Un Melkart de bronce en el Museo Arqueológico de Sevilla, Homenaje al prof. Martín Almagro Basch, Madrid, vol. III, 369-375.

FERNÁNDEZ URIEL, P. (2007): Bronces de los lararios domésticos, Metalistería en la Hispania romana (C. Fernández Ibáñez, ed.), Santander, 277-300.
GARCÍA ALFONSO, E. (2017): Aproximación a los fondeaderos fenicios de la bahía de Málaga y su evolución: paleogeografía y arqueología, Mazarrón II. Contexto, viabilidad y perspectivas del barco B-2 de la bahía de Mazarrón. En homenaje a Julio Mas García (M. Martínez, J. M. García, J. M. Blánquez, A. Iniesta, eds.), Madrid, 341-383.

GARCÍA DE LA LEÑA, C.; MEDINA CONDE, C. (1790): Conversaciones historicas malagueñas. Descanso II en que se da la Malaga romana, y sarracenica, Málaga.

GARCÍA Y BELLIDO, A. (1963): Hércules Gaditanus, AEspA 36, 70-153.

GEORGIEV, P. (1995): Bronze Figurines of Heracles from Moesia inferior, Acta of the 12 Congress of Ancient Bronzes (A. Gerhatl-Witteveen, ed.),Nijmejen, 261-265.

GIBBONS, S. E. (1975): The Labours of Heracles, a literary and artistic examination, Thesis of Doctor, London University.

HERODOTO (1982): Los nueve libros de la Historia, Barcelona.

HESÍODO (1975): Teogonía, Trabajos y Días, Barcelona.

HITA RUIZ, J. M.; VILLADA PAREDES, F. (2017): Museo de Ceuta: pasado, presente y futuro, Boletín del Museo Arqueológico Nacional 35, 1399-1414.

HUMBERT, J. (1984): Mitología griega y romana, Barcelona.

HUNT ORTIZ, M. A. (2014): Memoria final de un bronce romano con representación de Hércules. Museo de Málaga, informe inédito, Sevilla.

JENSEN, R. (2002): Melqart and Herackles: A Study of Ancient Gods and their influence, Studia Antiqua 2 (2), 101-109.

JIMÉNEZ ÁVILA, J. (2002): La toréutica orientalizante en la Península Ibérica, Madrid.

MALGIERI, A. (2008): Un bronzetto di Hercules e il culto di Ercole a Iasos, Blasos 14, 24-29.

MARTín RUIZ, J. A. (2010): Hiram I, rey de Tiro, Herakleion. Revista Interdisciplinar de Arqueología e Historia del Mediterráneo 3, 7-35.

MARTÍN RUIZ, J. A. (2018): Malaca. De colonia fenicia a municipio romano, Ronda.

MEDEROS MARTÍN, A. (2009): La fundación de la ciudad de Gadir y su primer santuario urbano de Astarté-Afrodita, Isimu. Revista sobre Oriente Próximo y Egipto en la Antigüedad 13, 183-207.

MORA SERRANO, B. (1981): Sobre el templo de las acuñaciones malacitanas, Jábega 35, 37-42.

MORENO, P. (1995): Il Melqart di Mozia: dal dio di Tiro all'Eracle di Lissipo, I Fenici: ieri oggi domani. Richerche, scoperte, progetti (E. Acquaro, ed.), Roma, 545-552.

MORENO PULIDO, E. (2014-2015): Imágenes arcaizantes de Melqart: figurando el Heracles egipcio. Nuevas hipótesis de interpretación desde la iconografía monetaria malacitana y mauritana, Byrsa. Scritti su'll antico oriente mediterraneo 25-26/27-28, 149-183.

ORIA SEGURA, M. (1993): El Hércules de Carteia en época imperial, Almoraima. Revista de Estudios Campogibraltereños 9, 163-174. 
ORIA SEGURA, M. (1996): Hércules en Hispania: una aproximación, Barcelona.

ORIA SEGURA, M. (2002): Religión, culto y arqueología: Hércules en la Península Ibérica, Ex Oriente Lux: las religiones orientales en la Península Ibérica (E. Ferrer Albelda, ed.), Sevilla, 219-243.

ORIA SEGURA, M.; ESCOBAR PÉREZ, B. (1994): Dioses romanos en bronce de la Bética occidental. Propuesta de interpretación, Arqueología en el entorno del Bajo Guadiana (J. M. Campos, J. Aurelio Pérez, F. Gómez, eds.), Huelva, 441-467.

PALAGIA, O. (1990): Two statues of Hercules in the Forum Boarium in Rome, OJA 9 (1), 51-70.

DOI: https://doi.org/10.1111/j.1468-0092.1990.tb00215.x

PÉREZ-MALUMBRES LANDA, A. (2012): Contextos comerciales de la transición de la Malaka fenicia a la romana en los solares de calle Granada, 57-61, La etapa neopúnica en Hispania y el Mediterráneo centro occidental: identidades compartidas (B. Mora Serrano, G. Cruz Andreotti, coords.), Sevilla, 361-389.

PÉREZ-MALUMBRES LANDA, A. (2018): Sello cerámico de panadero de época romana con representación del Dextrarum Iunctio, procedente de Málaga, Albhari.Entre Oriente y Occidente. Revista Independiente de Estudios Históricos 5, 83-98.

PÉREZ ZURITA, A. (2011): Control y administración de pesos y medidas en las ciudades del Imperio romano (Pars Occidentalis), Gerión 29, 1, 123-148.

DOI: https://doi.org/10.5209/rev_GERI.2011.v29.n1.39048

POVEDA NAVARRO, A. M. (1999): Melqart y Astarté en el occidente mediterráneo: la evidencia de la presencia ibérica (siglos VIII-VI a.C.), De Oriente a Occidente: los dioses fenicios en las colonias occidentales, XII Jornadas de Arqueología fenicio-púnica (B. Costa, J. H. Fernández, eds.), Eivissa, 25-61.

REBUFFAT, R. (1971): Bronzes antiques d'Hercule à Tanger et à Arzila, Antiquités Africaines 5, 179-191. DOI: https://doi.org/10.3406/antaf.1971.926

RODRÍGUEZ MARTORELL, F.; RUIZ DE ARBULO, J. (2016): Un aequipondium de peso excepcional y la balanza pública del puerto de Tarraco, AEspA 89, 163-180. DOI: https://doi.org/10.3989/aespa.089.016.008

RODRÍGUEZ OLIVA, P. (1988): Pequeños bronces romanos de Ceuta, Actas del Congreso Internacional El Estrecho de Gibraltar (E. Ripoll Perelló, ed.), Ceuta, vol. I, 907-917.

RODRÍGUEZ OLIVA, P. (1990): Los bronces romanos de la Bética y la Lusitania, Los bronces romanos en España: catálogo de la exposición, Madrid, 91-102.

SÁNCHEZ CANTÓN, F. J. (1943): La primera colección española de cuadros y estatuas que tuvo un catálogo impreso, Boletín de la Real Academia de la Historia 111, 217-227.

SÁNCHEZ DE LA TORRE, M. N. (2016): La religión romana en Hispania, Tesis Doctoral, Universidad Complutense de Madrid.

VELÁZQUEZ, F.; LÓPEZ-GRANDE, M. J.; MEZQUIDA, A.; FERNÁNDEZ, J. H. (2015): Nuevos estudios sobre escarabeos hallados en Ibiza, Eivissa.

VIVES I ESCUDERO, A. (1917): Estudios de Arqueología cartaginesa. La necrópoli de Ibiza, Madrid.

ZAMBRANO VALDIVIA, L. C. (2010): Estatuillas de Melkart, Cádiz y Huelva. Puertos fenicios del Atlántico (M. D. López de la Orden, E. García Alfonso, eds.), Sevilla, 228-229. 